Bioscientia Medicina: Journal of Biomedicine \&

Translational Research

Journal Homepage: www.bioscmed.com

\title{
Preliminary Result in Endoscopic Video Assisted Breast Surgery Randi Dwiyanto ${ }^{1 *}$, Kristanto Yuli Yarso ${ }^{2}$
}

${ }^{1}$ Department of Surgery, Faculty of Medicine, Sebelas Maret University, Surakarta, Indonesia

2 Department of Surgery, Oncology Division, Faculty of Medicine, Sebelas Maret University, Surakarta, Indonesia

\section{A R T I C L E I N F O}

Keywords:

Video assisted breast surgery

Endoscopic

Benign breast tumor

Surakarta

\section{*Corresponding author:}

Randi Dwiyanto

E-mail address:

\section{Randidwnt@gmail.com}

All authors have reviewed and approved the final version of the manuscript.

\section{A B S T R A C T}

Background: The development of technology has grown rapidly in surgical science, especially the use of endoscopy to develop operations in producing minimal scar tissue. Endoscopic VABS is a surgical technique and began to develop since 1995. The technique has several approaches, namely through the chest wall, mammary and axilla. The descriptive study aims to report our first experience in the management of benign breast tumors with Endoscopic Video Assisted Breast Surgery. Methods: Ten patients with benign breast tumor have performed Endoscopic VABS in the period March 2017 to September 2017 at the Hospital in Surakarta. The largest diameter at the nodule, duration of operation, length of postoperative care, postoperative pain, cosmetic outcomes and complications were observed retrospectively. Results: All patients are women with median age 28 years. The largest diameter that can be taken is $3.5 \mathrm{~cm}$ with median $2 \mathrm{~cm}$. One patient performed the conversion into a lumpectomy with conventional techniques due to difficult dissection and uncontrolled bleeding. The median duration of surgery was 60 minute with an average length of treatment for 2 days postoperatively. Average VAS Score was 4 . No postoperative complications were found. But cosmetically, all patients are satisfied with the results of surgical wounds. Conclusion: The VABS endoscopic procedure is safe and effective procedure and has excellent cosmetic benefits because it does not show scar tissue in the breast area. This VABS Endoscopic technique has a weakness in terms of longer duration of operation compared to conventional techniques, but this can be overcome with the expertise and experience of the operator.

\section{https://doi.org/10.32539/bsm.v5i11.420}

\section{Introduction}

Since 1992, video-assisted surgery for the breast has been developed mainly in the field of plastic surgery, notably in breast augmentation surgery. ${ }^{1}$ Today, video-assisted surgery, indicating partial or total endoscopic surgery, can be performed for the treatment of both benign and malignant breast tumors to improve the cosmetic outcome. Although, in some respects, this kind of surgery for malignant tumors is still experimental, it is feasible enough for clinical use, and is expected to become one of the standard operations for breast cancer.1,2,3

Breast surgery is indicated for early-stage breast cancer. However, whenever the disease is at an early stage, BCS does not for some breast cancers, ductal breast cancer, and ductal carcinoma in situ (DCIS), due to the need for extensive breast resection.2,4 There is a new endoscopic surgery called video-assisted breast surgery (VABS). The VABS has three main features workspace is made by retraction method. Almost all surgical procedures are performed through a small axillary incision. ${ }^{4}$ Breast reconstructed simultaneously to keep the form of surgery.

\section{Methods}

Ten patients with benign breast tumor have performed Endoscopic VABS in the period March 2017 to September 2017 at the Hospital in Surakarta. The largest diameter at the nodule, duration of operation, 
length of postoperative care, postoperative pain, cosmetic outcomes and complications were observed retrospectively.

\section{Discussion}

It has been reported, the first patient The 23-yearold woman came to the surgical oncology clinic, came with a lump complaint on the right breast since 1 month before admission, the first lump felt small for the marbles seed and did not get bigger, no fluid came out of the breast nipple, no bumps in other places. Of family history no one has ever experienced breast cancer.

From the physical examination, the patient was of moderate pain, with blood pressure $110 / 70 \mathrm{mmHg}$, heart rate $74 \times$ / $\min$, respiratory rate 20 x / min, temperature $36,3^{\circ} \mathrm{C}$. Generalized status within normal limits. The conjunctiva is not anemic and the sclera is not jaundiced. From the right localist status of the right breast was obtained a mass of $2 \mathrm{x} 1 \mathrm{x} 2 \mathrm{~cm}$ in size, with a supple consistency, mobile, no peau de orange, no satelite nodules, no secretions coming out of the breast. From examination of lymph gland in supraclavicula, infraclavicula, axilla dextra and sinistra, mass was not found.

From the laboratory examination of blood found $\mathrm{Hb}$ $13.5 \mathrm{gr} / \mathrm{dl}$, leukocyte 6,400 / mm3, 39\% hematocrit, 180.000 / mm3 platelet.

Patients was performed investigations with ultrasound of mammae, the results obtained solid mass tended to a benign lesion.

The second patient The 22-year-old woman came to the surgical oncology clinic, coming with a lump complaint on the left breast since 3 months before admission, the first lump felt small by the seed of the marbles then grew, no fluid came out of the nipples, no bumps on the spot other. From a family history found there who have experienced breast cancer, the patient grandmother.

From the physical examination, the patient was of moderate illness, with blood pressure 110/60 mmHg, heart rate $78 \times$ / $\min$, respiratory rate $20 \mathrm{x} / \mathrm{min}$, temperature $36,5^{\circ} \mathrm{C}$. Generalized status within normal limits. The conjunctiva is not anemic and the sclera is not jaundiced. From the localist status of the left breast is obtained a mass of $2 \mathrm{x} 2 \mathrm{x} 2 \mathrm{~cm}$ in size, with the consistency of rubbery, mobile, no peau de orange, no satelite nodules, no secretions coming out of the breast. From examination of lymph gland supraclavicula, infraclavicula, axilla dextra and sinistra, mass was not found.

From the laboratory examination of blood found $\mathrm{Hb}$ $12.6 \mathrm{gr} / \mathrm{dl}$, leucocyte 7,200 / mm3, 37\% hematocrit, 190.000 / mm3 platelet.

In addition, patients performed investigations with ultrasound, which obtained cyst results in the left superolateral quadrant.

Both patients had surgery performed with Video Assisted Breast Surgery (VABS). The VABS has three main features:

- Workspace is made by retraction method

- Almost all surgical procedures are performed through a small axillary incision

- Breast reconstructed simultaneously to maintain preoperative breast form

This procedure is used for various breast diseases, including benign tumors of large size and extensive malignant disease without skin invasion. This procedure is expected to improve the quality of life of patients with breast disease.

VABS requires only $2.5 \mathrm{~cm}$ of wound in the axilla. Opening can be done from trans axillary. No incision is required on the breast skin. VABS is less invasive and aesthetically better for benign and malignant diseases. 


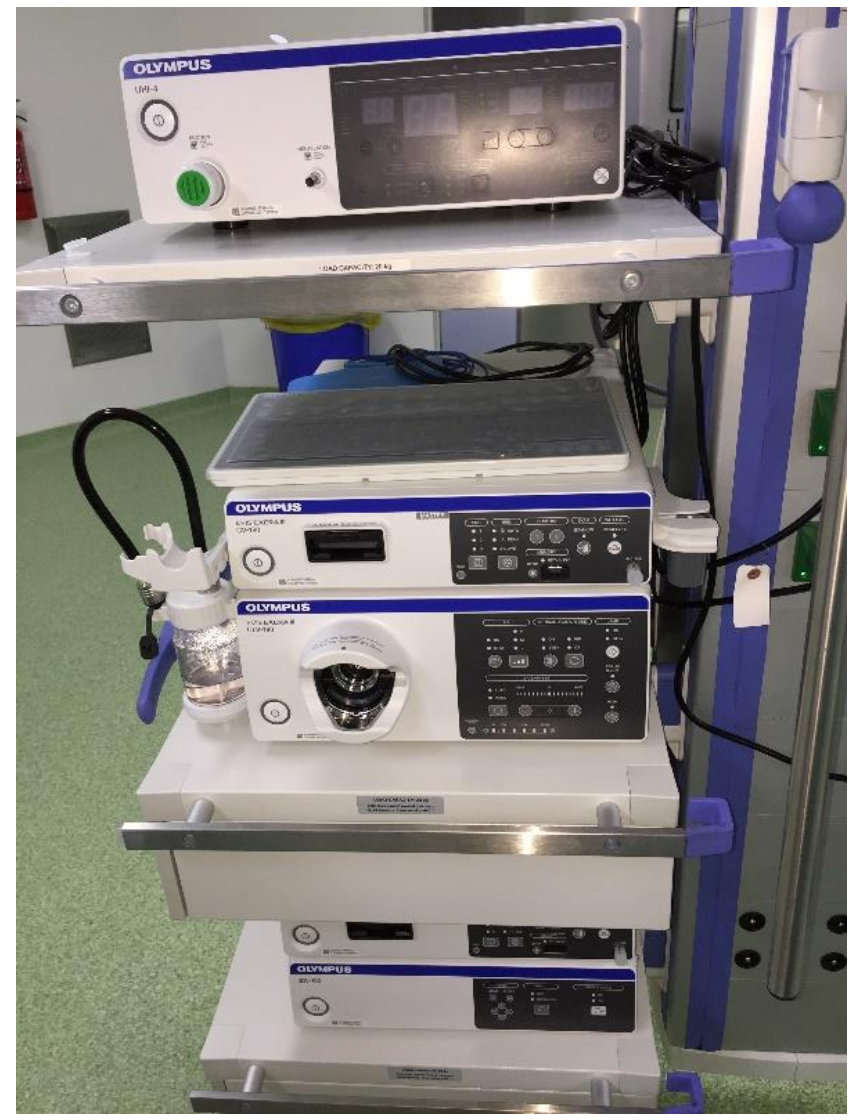

Figure 1. Video Assisted Breast Surgery (VABS)

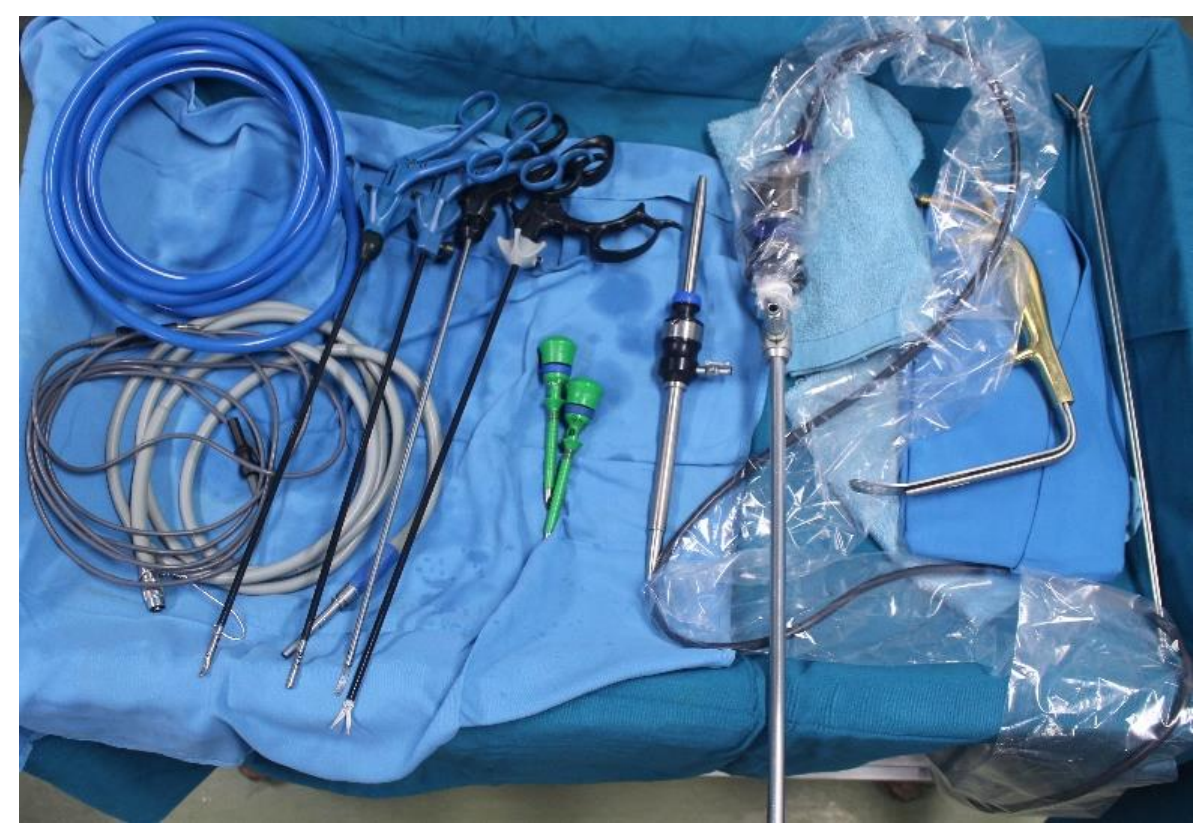

Figure 2. Equipment for Video Assisted Breast Surgery (VABS) 


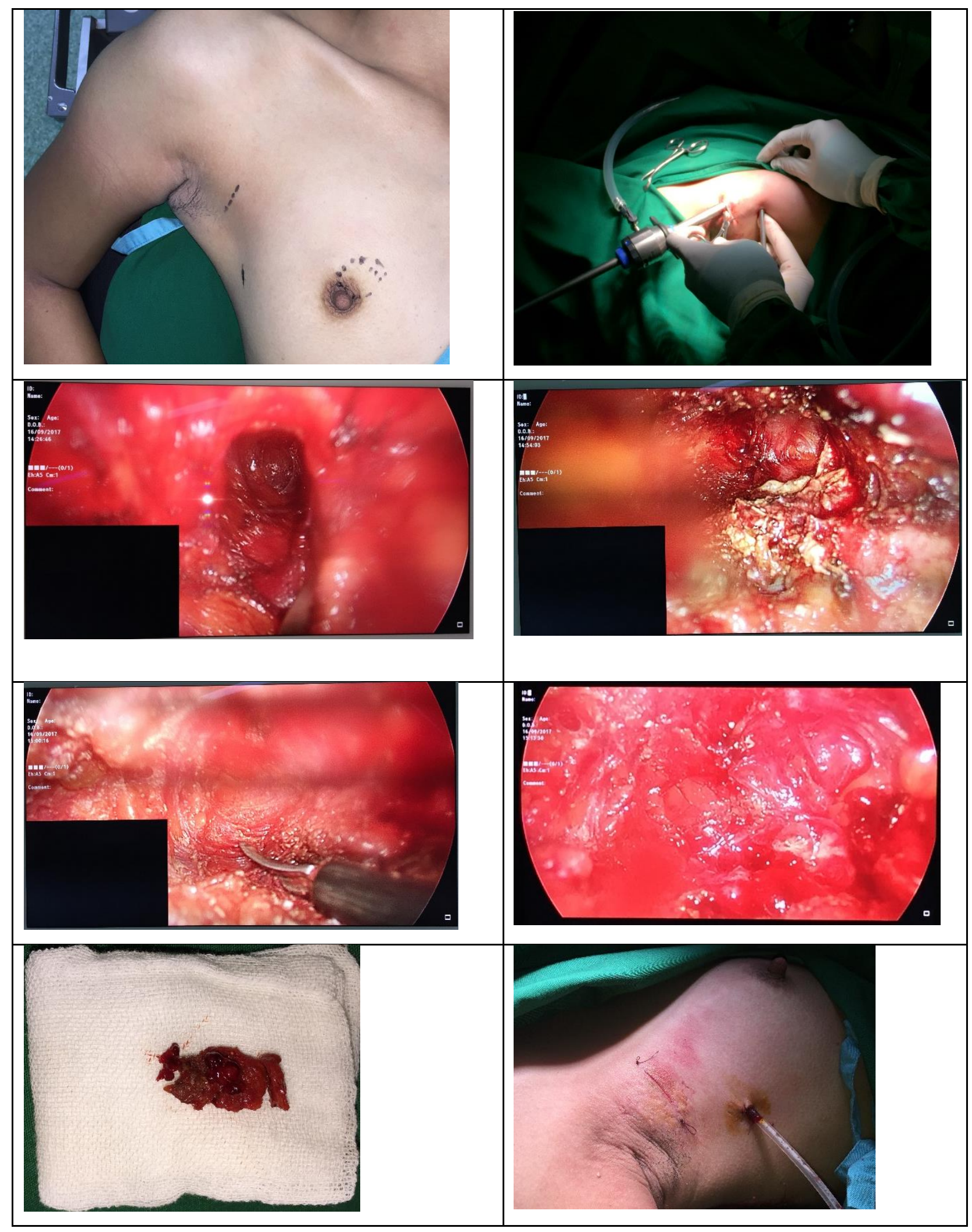

Figure 3. The procedure of Video Assisted Breast Surgery (VABS) 


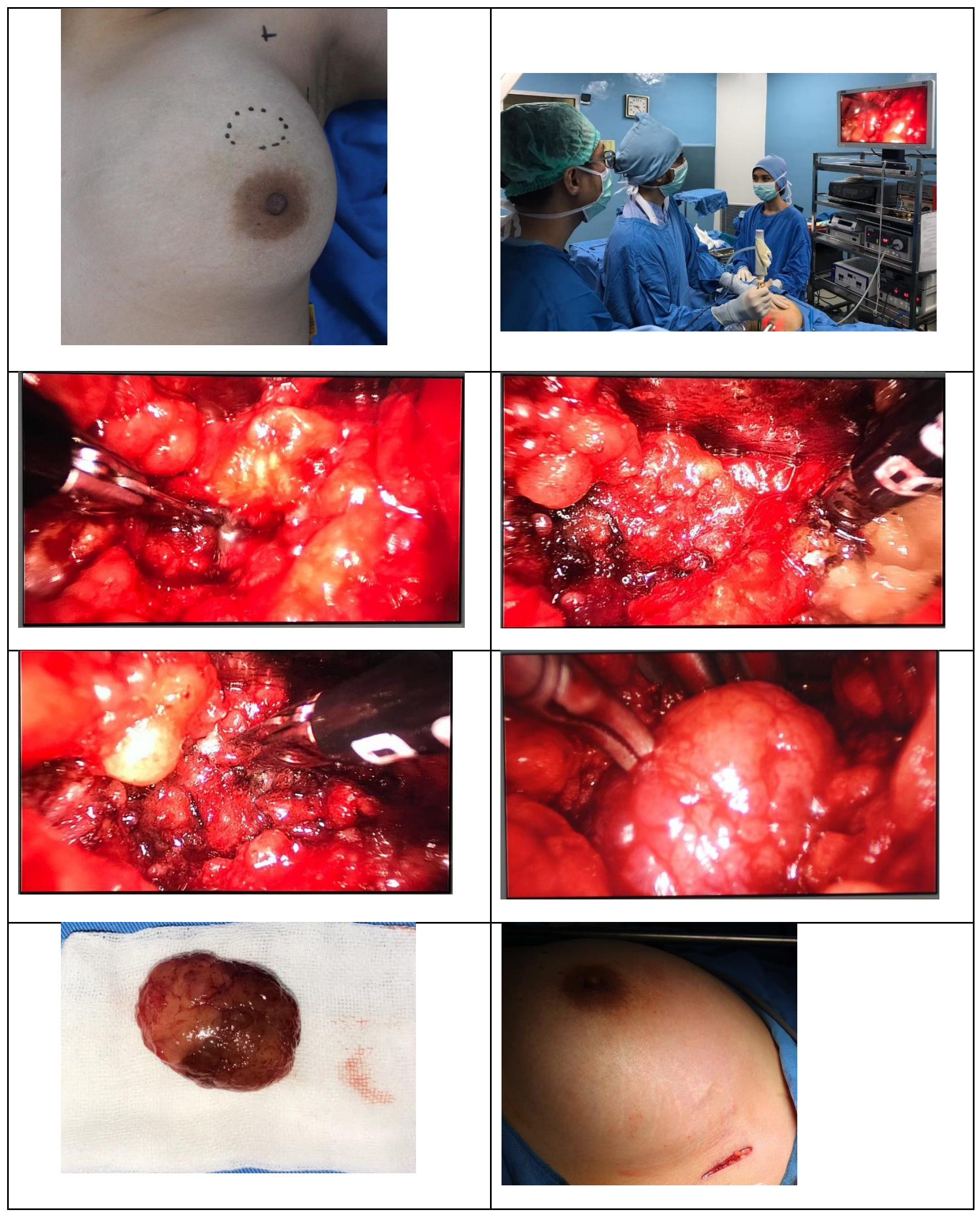

Figure 4. The procedure of Video Assisted Breast Surgery (VABS) 


\section{Results}

All patients are women with median age 28 years. The largest diameter that can be taken is $3.5 \mathrm{~cm}$ with median $2 \mathrm{~cm}$. One patient performed the conversion into a lumpectomy with conventional techniques due to difficult dissection and uncontrolled bleeding. The median duration of surgery was 60 minutes with an average length of treatment for 2 days postoperatively. Average VAS Score was 4. No postoperative complications were found. But cosmetically, all patients are satisfied with the results of surgical wounds.

\begin{tabular}{|c|c|c|c|}
\hline No. & Name & Location & Size \\
\hline 1. & Ms. P / 23 y.o & $\begin{array}{l}\text { Superolateral (D) } \\
\text { quadrant }\end{array}$ & $2 \mathrm{x} 1 \mathrm{x} 1 \mathrm{~cm}$ \\
\hline 2. & Ms. Y / 22 y.o & $\begin{array}{l}\text { Superomedial }(\mathrm{S}) \\
\text { quadrant }\end{array}$ & $3,5 \times 3,5 \times 2,5 \mathrm{~cm}$ \\
\hline 3. & Mrs. A / 27 y.o & $\begin{array}{c}\text { Superomedial (S) } \\
\text { quadrant }\end{array}$ & $2 \times 2 \times 2 \mathrm{~cm}$ \\
\hline 4. & Mrs. H / 35 y.o & $\begin{array}{l}\text { Superomedial (D), } \\
\text { Inferolateral (D) + } \\
\text { Superomedial (S) } \\
\text { quadrant }\end{array}$ & $\begin{array}{c}3,5 \times 2,8 \times 2,5 \mathrm{~cm}, 2,8 \times 1,5 \times 1 \mathrm{~cm}+ \\
3,5 \times 1,8 \times 1,4 \mathrm{~cm}\end{array}$ \\
\hline 5. & Mrs. I / 51 y.o & $\begin{array}{l}\text { Superomedial (D) } \\
\text { quadrant }\end{array}$ & $2 \times 2 \mathrm{~cm}$ \\
\hline 6. & Mrs. A / 33 y.o & $\begin{array}{l}\text { Superolateral }(\mathrm{S}) \\
\text { quadrant }\end{array}$ & $3,5 \times 1,2 \times 1 \mathrm{~cm}$ \\
\hline 7. & Mrs. E / 46 y.o & $\begin{array}{l}\text { Superolateral (D) + } \\
\text { Superomedial (S), } \\
\text { Superolateral (S) } \\
\text { quadrant }\end{array}$ & $3,5 \times 1,5 \times 1 \mathrm{~cm}+1 \times 1 \mathrm{~cm}, 1 \times 1 \mathrm{~cm}$ \\
\hline 8. & Ms. A / 19 y.o & $\begin{array}{c}\text { Superomedial (D) } \\
\text { quadrant }\end{array}$ & $1 \times 2,5 \times 2 \mathrm{~cm}$ \\
\hline 9. & Ms. A / 21 y.o & $\begin{array}{c}\text { Superolateral }(\mathrm{S})+ \\
\text { Inferolateral }(\mathrm{S}) \\
\text { quadrant }\end{array}$ & $3,2 \times 5 \times 2 \mathrm{~cm}+1,5 \times 1,5 \times 1 \mathrm{~cm}$ \\
\hline 10. & Mrs. R / 29 y.o & $\begin{array}{c}\text { Superomedial (D) } \\
\text { quadrant }\end{array}$ & $2 \times 1,8 \times 1,2 \mathrm{~cm}$ \\
\hline
\end{tabular}

Figure 5. The result of Video Assisted Breast Surgery (VABS) 
Fibroadenoma is the most common histologic subtype of benign breast tumors. We found that most of the patients were young, located far away from the areolar complex.

A circumareolar incision, which leaves the least visible scar, is a common approach for the management of benign breast lesions. The cosmetic result is favorable, and the tumor can usually be adequately resected.

The main limitation of performing endoscopy-assisted breast surgery is the need for general anesthesia and hospitalization. In fact, some patients were discharged the same day after recovery from anesthesia.

\section{Conclusion}

In conclusion, this newly devised TARM approach leaves no injury on whole breast skin, and can become a single standard method for breast-conserving surgery wherever the cancer is situated.

The cosmetic results and patient satisfaction were very good and justified the time and effort spent to perform VABS. ${ }^{3,11}$ As the induration due to postoperative inflammation become softer with time, the cosmetic results and satisfaction improve. We are now improving the methods of breast reconstruction to improve outcomes further.

The early postoperative complications were less severe than those with conventional surgery and were acceptable.7,9 Locoregional recurrence was not observed. However, strict follow-up is needed because the average follow-up time was on average and 50 months at most. Therefore this operation is adequate as a breast cancer therapy.

VABS has mainly been performed for patients with early breast cancer. However, the patients with multiple or large benign tumors are also good candidates for this surgery. ${ }^{11}$ The largest tumor we treated with VABS was a fibroadenoma $6.5 \mathrm{~cm}$ in diameter. VABS is a good surgical procedure for such benign diseases, because the patients are young and conventional surgeries produce multiple or long, unattractive wound scars on the breast skin. VABS makes only a small wound scar in the inconspicuous axillary area.
Diffuse DCIS is an early breast cancer; however, it spreads to the entire mammary gland and requires mastectomy for cure.11,12 Skin-sparing total mastectomy has become a standard therapy. Diffuse DCIS is also a good candidate for VABS. We performed VABS skin-sparing total mastectomy in 2 patients. One patient underwent simultaneous breast reconstruction with a silicon gel prosthesis.

We will perform VABS in more patients with breast cancer, if it is able to consistently achieve complete recovery.

VABS is an effective method of surgery for breast diseases and achieves good aesthetic results. Furthermore, the early and late postoperative complications associated with this procedure are acceptable.

\section{References}

1. Schwartz GF, Giuliano AE, Veronesi U Proceedings of the consensus conference on the role of sentinel lymph node biopsy in carcinoma of the breast April 19 to 22, 2001, Philadelphia, Pennsylvania. Cancer. 2002; 94: 25422551CrossRefPubMedGoogle Scholar

2. Suga K, Ogasawara N, Okada M, Matsunaga N Interstitial CT lymphography-guided localization of breast sentinel lymph node: preliminary results. Surgery. 2003; 133: 170179CrossRefPubMedGoogle Scholar

3. Tangoku A, Yamamoto S, Suga K, Ueda K, Nagashima Y, Hida M, Sato T, Sakamoto Y, Oka M. Sentinel lymph node biopsy using computed tomography-lymphography in patients with breast cancer. Surgery. 2004; 135:258265CrossRefPubMedGoogle Scholar

4. Minato M, Hirose C, Sasa M, Nishitani H, Hirose Y, Morimoto T. 3-Dimensional computed tomography lymphography-guided identification of sentinel lymph node in breast cancer patients using subcutaneous injection of nonionic contrast medium: a clinical trial. J Comput Assist Tomogr. 2004; 28: 4651CrossRefPubMedGoogle Scholar. 
5. Yamashita K, Shimizu K Endoscopic videoassisted breast surgery: procedures and shortterm results. J Nippon Med Sch. 2006; 73: 193202CrossRefPubMedGoogle Scholar

6. Yamagata M, Takasugi T, Takayama T Partial mastectomy by the periareolar incision. Geka Chiryo. 2002; 86:932-940Google Scholar

7. Goldhirsch A, Wood WC, Gelber RD, Coates AS, Thurlimann B, Senn HJ Meeting highlights: updated international expert consensus on primary therapy of early breast cancer. J Clin Oncol. 2003; 21: 33573365CrossRefPubMedGoogle Scholar

8. Suga K, Yamamoto S, Tangoku A, Oka M, Kawakami Y, Matsunaga N. Breast sentinel lymph node navigation with three-dimensional multidetector-row computed tomographic lymphography. Invest Radiol. 2005; 40: 336342CrossRefPubMedGoogle Scholar
9. Ernst MF, Voogd AC, Balder W, Klinkenbij1 JH, Roukema JA. Early and late morbidity associated with axillary level I-III dissection in breast cancer. J Surg Oncol. 2002; 79: 151155CrossRefPubMedGoogle Scholar

10.Schrenk P, Rieger R, Shamiyeh A, Wayand W Morbidity following sentinel lymph node biopsy versus axillary lymph node dissection for patients with breast carcinoma. Cancer. 2000; 88: 608-614. CrossRefPubMedGoogle Scholar

11.Mariani G, Moresco L, Viale G, Bagnasco M, Canavese G, Buscombe J, Strauss HW, Paganelli G Radioguided sentinel lymph node biopsy in breast cancer surgery. J Nucl Med. 2001; 42: 1198-1215PubMedGoogle Scholar

12.Yamashita K, Takushima M, Hioki M, Shimizu K Indication extension of video-assisted breast surgery after preoperative systemic therapy for advanced breast cancer. Breast Cancer. 2007. 